\title{
Medical education and training in Nepal: SWOT analysis
}

\section{Dixit $\mathrm{H}^{1}$, Marahatta $\mathrm{SB}^{2}$}

${ }^{1}$ Professor, Department of Paediatrics, Kathmandu Medical College, Sinamangal, Nepal; ${ }^{2}$ Lecturer, Department of Community Medicine, Kathmandu University School of Medical Sciences, Dhulikhel, Nepal

\begin{abstract}
Objective: To analyse the impact of the medical colleges that have been set up within the last two decades by production of the doctors and the effect on the health of the people

Materials and methods: SWOT (strength, weakness, opportunities and threats) analysis of medical education in Nepal has been done by reviewing medical manpower produced by the different institutions in the undergraduate and postgraduate $(\mathrm{PG})$ categories, their registration with the Nepal Medical Council in terms of the existing health scenario of the country

Results: Shows severe shortage of basic sciences teachers. In the clinical areas ophthalmic manpower and services provided are exemplary. There are shortages and shortcomings in all areas if standard health care is to be provided to the Nepalese. There is a long way to go to provide the expected educational and medical services to foreigners prepared to pay more to avail of this in Nepal.
\end{abstract}

Key words: HRH, undergraduate, PG, basic sciences, clinical, medical tourism.

$\mathrm{T}$ he doctor per population ratio in Nepal of 1992 was $1: 15,800$ of the population $(0.063 \text { per } 1000)^{1}$ but now it has reached to 0.24 per 1000 as of $2008^{2}$. Compared to this, Cuba had 5.91 doctors for 1,000 people in 2002, India had 0.6 doctor $^{3}$ Malawi had 0.02 per 1000 as of $2007^{4}$.

The country now has 6970 medical doctors and 705 dental surgeons as of Aug 10,2008 to serve an estimated $29,519,114$ population ${ }^{2}$. Furthermore, most doctors and health facilities are concentrated in the urban areas and in the relatively developed Central and Western development regions, as opposed to the Eastern, MidWestern and Far-Western regions ${ }^{5}$. With a population of nearly 250,000, Achham, one of Nepal's poorest districts, has only one hospital and 75 health units. The only fully trained government medical workers are the 15 health assistants, 40 assistant health workers and eight auxiliary nurses for the whole district. This health situation is very worrisome as in Achham, a large number of infants die of diarrhoea. One of key reasons for so many deaths and a worsening health situation in rural areas is the shortage of medicines and lack of a regular supply. The shortage of doctors in rural areas has always been a problem despite the government's efforts to recruit them to work in the villages ${ }^{6}$.

\section{Strengths}

Over the last decade Nepal has succeeded in setting up a complex medical and health infrastructure involving teaching, training, research, drugs and medical equipment production, and healthcare, even at the tertiary level. There is no denying of the many achievements over the decades - increased life expectancy, reduced infant mortality, declines in fertility, some success in eradicating basic communicable diseases. With dramatic increases of the number of medical school in the last decade, universities and regulatory bodies (e.g. Nepal Medical Council) face difficult task of providing quality medical education?

\section{Medical institutions}

Historically training of the paramedical staff (compounders and dressers) for the health services of Nepal started at the Central Medical School established at Kathmandu as far back as 1934 AD for the production of Human Resources of Health (HRH). The idea of starting a Medical School with the aid of WHO was first thought about in $1963^{8}$. The Civil Medical School later developed in 1972 into the Institute of Medicine to train different grades of manpower or the Human Resources of Health (HRH). The medical course which started in 1984 was different from the traditional one and centred on the concepts of community orientation, system wise

\section{Correspondence}

Prof. Hemang Dixit

Consultant Paediatrician and Principal

Kathmandu Medical College, Sinamangal, Kathmandu

E-mail: h2dixit@gmail.com 
instruction and problem based learning. It is these health workers who are the backbone of the health services.

It was however many years later in 1978 that Tribhuvan University (TU), Institute of Medicine (IoM) started the MBBS course and the first MBBS doctor graduated in 1984. It may be said that there have been tremendous changes in the health sector since then. Later the BP Koirala Institute of Health Sciences (BPKIHS) at Dharan was established in 1993 as a deemed university, to be followed by Kathmandu University (KU) in 1994 for the production of the middle and higher levels of health manpower ${ }^{7}$. The medical courses at both those institutions continued further along the non-traditional MBBS path. The concept of a SPICES model expanded as student centred, problem based, integrated, community oriented, with electives and systematic teaching was stressed upon.

Production of other grades of HRH is now supervised by the Council of Technical Education and Vocational Training (CTEVT), which oversees the standards in almost 200 institutions scattered all over the country. In the early eighties or nineties of the last century, a number of basic and middle level manpower were going for work to some of the countries in the Gulf. In this new millennium some higher grades of manpower such as doctors and nurses are going much further afield to North America, Australia and to a lesser extent to the United Kingdom. Besides this, a number of Nepalese are going to neighbouring countries such as India, China and Bangladesh in substantial numbers for HRH training in different subjects.

Why has all this occurred? It is partly due to a worldwide phenomenon of student movement in which there has been great investment and also great returns. The turnover is in billions, irrespective of which currency one is calculating in. This worldwide trend has influenced and led to the development of both Education and Health sectors as possible service industries in Nepal. These two projected service industries of the future are going to expand and grow only if we can ensure that the products which come out and the services provided are of the specific required standards. It is therefore essential to ensure that the quality education and training is of very high standards.

\section{Medical Colleges}

In 2007 the number of Medical / Dental Colleges in Nepal was 3 in the Public or government sector and 13 in the Private sector ${ }^{2}$. By mid 2008 this is in the process of changing as given in Table 1.

\section{Public institutions}

Tribhuvan University Institute of Medicine: Undergraduate and Post Graduates.

BP Koirala Institute of Health Sciences. Medical \& Dental Undergraduate and Post Graduates in certain areas.

National Academy of Medical Sciences based at Bir Hospital and other Government Hospitals in Kathmandu valley: Post Graduate training only

Private Medical Colleges. -

There are 3 under TU and 7 under KU.

Under Tribhuvan University

Universal College of Medical Sciences, Bhairahawa. Medical \& Dental Undergraduates

National Medical College, Birgunj.

Janaki Medical College, Janakpur.

\section{Under Kathmandu University}

Kathmandu University School of Medical Sciences, Dhulikhel.

Manipal College of Medical Sciences, Pokhara

College of Medical Sciences - Nepal, Bharatpur.

Kathmandu Medical College, Sinamangal,

Kathmandu.

Nepal Medical College, Jorpati, Kathmandu.

Nepalgunj Medical College, Nepalgunj.

Nobel Medical College, Biratnagar.

Of the medical colleges in pipeline, the Patan Academy of Health Sciences (PAHS) in the public sector, which is also going to be a deemed university, is planning to start functioning from early 2009. Another public sector college expected to start is the one from the Police Hospital. Other colleges expected to start sometime in the future are those that have been issued letters of intent and a sort of preliminary visit has been made to their sites. These are in the private sector and are four in number:

KIST Medical \& Dental College to be affiliated to TU. Lumbini Medical College.

Chitwan College of Medical Sciences

Deva Daha Medical College \& Research Centre

Private Dental Colleges

Affiliated to Tribhuvan University

Peoples Dental College, Kathmandu

Dental College of UCMS Bhairahawa.

MK Kedia Dental College, Birgunj. 


\section{Kathmandu University.}

Kantipur Dental College, Basundhara. Kathmandu.

Examining the figures one realises that the number of students studying medicine in Nepal alone is approximately 1200 per year. Another $800 / 1000$ would be going to countries such as India, China, Bangladesh and Philippines to study medicine. However of those 1200 studying in Nepal, about 300 would be foreign students who would leave the country after finishing their studies.

\section{Quality of intake}

It is accepted that the medical course and profession are very demanding and therefore not suitable for everyone. Competition for medical seats is intense, entrants to medical school are usually of a high academic standard, and their application (at least with respect to passing exams) is often exemplary. Almost all medical students in Nepal are about 18-20 years old and have just completed $10+2$ or A levels. They are also exclusively limited to science backgrounds (Physics, Chemistry and Biology) ${ }^{7}$. One of the realities considering medical students in Nepal is that many are not mature by age to feel the responsibilities of medical students. Fair percentages of the students miss classes on the slightest pretext, avoid assessments, presentations and are thus very irregular in attendance. This may be related to not only the lack of motivation but also to the standard of teaching which is not interesting enough or not up to the standard. Fortunately many of the students have inherent capabilities. The IoM selects 40/50 students from an entrance test in which there are generally over 1200 applicants. The successful ones need some guidance on what and how to study. In spite of many classes that may not be taken and the innumerable cultural and sports activities, most of the students come out with flying colors. But what about private medical colleges where an important criterion is the capacity to self finance ones education? Is this going to have a bearing on the quality of the future doctors produced in Nepal? Will they try to recoup as quickly as possible the financial inputs that they have made for acquiring their medical qualifications? ${ }^{9}$

\section{Curriculum}

Though the curriculum of TU IoM, envisaged integrated teaching, the reality is that the pre clinical subjects are taught separately. Some form of coordination and concurrence is maintained by teaching the same system in the different subjects. Phase II (3rd year) lasts for one year. Phase III encompasses another one and half years. The total course of the IoM is of 7098 hours of which 1889 is for Basic Sciences and 5209 for Clinical Sciences (The second version of the curriculum states it to be 8221 hours). Following this there is a one-year period of compulsory rotating internship. The reason for this choice of internship was that the product of the IoM should have a workable knowledge in all areas of medicine and surgery and thus be capable of working in any part of Nepal. It is worthwhile looking at the curriculum of the three MBBS courses in Nepal. When BP Koirala Institute of Health Sciences (BPKIHS) and Kathmandu University (KU) curriculum were compared in their Phase I and Part I respectively it was found that a total of 887 hours of theory and 793 hours of practical classes are allotted by BPKIHS whereas 1194 hours of theory classes and 963 hours of practical classes are allotted by $\mathrm{KU}^{3,4,5,6}$. It may be noted that the teaching of Basic Medical Sciences in an integrated, system and with a problem solving approach is the stated objective of all the three curricula of TU, BPKIHS and $\mathrm{KU}^{9}$.

\section{Existing manpower situation}

The Medical and Dental manpower or the Human Resources for Health existing in the country as per the records of the Nepal Medical Council up to the $10^{\text {th }}$ of August 2008, is as follows:

Registered Nepali medical doctors: Male 4719; Female 2241; Total 6960

Registered Nepali dental surgeons: Male 284; Female 421; Total 705

These figures though up-to-date are neither authoritative nor are they helpful as they do not tell us the exact number of doctors or dental surgeons in the country. Though obligatory to bring out an Annual Register of those registered with it, the NMC has not been able to do this since 2001. This seems surprising considering the fact that the NMC had brought out the list of eligible voters for the elections held in 2005. This could have easily led to an updated register. It is estimated that as much as 500 to 700 doctors may be going out of Nepal to countries such as USA, UK, Australia and South Africa. This inaccuracy also applies to dental surgeons. In their case, however, many female dental surgeons though abroad are not working there professionally but instead are accompanying their husbands abroad as housewives.

However the number of provisionally registered doctors has been increasing rapidly during the past 5 years viz. from 742 in 2061/62 BS it shot up to 1285 in 2064/65 BS. This figure includes the foreign students who have to do their internship training in Nepal prior to returning back to their own countries. The Nepali doctors would, at the end of their internship go on to become Temporary registered. The figures in this category went up from 507 in 2060/61 BS to 940 in 2064/65 BS. The figure of permanently registered doctors during the last five years is given in Table 2 . 
The total number of temporary and permanent registered doctors therefore is about 1500 year at any one time.

One of the surprising facts that seem to emerge is that the vital statistics about health indicators shows great improvement. One presumes that the figures are correct even as one ponders over the words "Statistics, more statistics and lies". One has always to give the benefit of doubt to figures that have been presented by the Ministry of Health.

\section{Specialists}

The registration of specialists up to the end of 2004 was a total of 562, of which 430 were males and 132 females. By the end of 2007 these figures had changed in the different specialities as shown in Table 3.

Table 1: Number of Medical and Dental schools in 2008

\begin{tabular}{|c|c|c|c|c|c|c|}
\hline Year & Medical & Colleges & Dental & Colleges & Colleges & In Pipeline \\
\hline 2008 & Public & Private & Public & Private & Public & Private \\
\hline 2009 & 4 & 10 & $\left(1^{*}\right)$ & $2+\left(1^{*}\right)$ & & $3+\left(1^{*}\right)$ \\
\hline
\end{tabular}

- Dental Colleges, which are incorporated in a Medical institution (*) e.g. BPKIHS \& UCMS, Bhairahawa.

- PAHS - Patan Academy of Health Sciences.

- KIST- Kathmandu Institute of Science \& Technology.

Table 2: Number of permanently registered doctors during the last five years

\begin{tabular}{|c|c|}
\hline Year & No. of doctors \\
\hline 2003 & 488 \\
\hline 2004 & 552 \\
\hline 2005 & 722 \\
\hline 2006 & 657 \\
\hline 2007 & 870 \\
\hline
\end{tabular}


Table 3: Registration of specialists up to the end of 2007 according to NMC Records

\begin{tabular}{|c|c|c|c|}
\hline Subject & Male & Female & Total \\
\hline Anaesthesiology & 43 & 16 & 59 \\
\hline Cardiology & 52 & 1 & 53 \\
\hline Clinical Pathology & 18 & 18 & 36 \\
\hline Community Medicine / Public Health & 15 & 6 & 21 \\
\hline Dental Surgery - Masters & 30 & 13 & 43 \\
\hline Dermatology / Venereology & 22 & 10 & 32 \\
\hline ENT & 32 & 7 & 39 \\
\hline Forensic Medicine & 3 & 0 & 3 \\
\hline Gastroenterology & 11 & 1 & 12 \\
\hline General Practice & 53 & 11 & 64 \\
\hline General Surgery & 137 & 7 & 144 \\
\hline Internal Medicine & 78 & 10 & 88 \\
\hline Microbiology & 1 & 1 & 2 \\
\hline Nephrology & 3 & 1 & 4 \\
\hline Neurology & 6 & 2 & 8 \\
\hline Nuclear Medicine & 3 & 0 & 3 \\
\hline Obstetrics \& Gynaecology & 56 & 100 & 156 \\
\hline Oncology & 3 & 0 & 3 \\
\hline Ophthalmology & 40 & 20 & 60 \\
\hline Orthopaedics & 94 & 1 & 95 \\
\hline Paediatrics & 90 & 31 & 121 \\
\hline Pharmacology & 7 & 0 & 7 \\
\hline Psychiatry & 24 & 1 & 25 \\
\hline Radiology \& Imaging & 52 & 6 & 58 \\
\hline Surgical Oncology & 7 & 0 & 7 \\
\hline TB and Respiratory Diseases & 4 & 1 & 5 \\
\hline Urology & 9 & 0 & 9 \\
\hline Total & 890 & 264 & 1154 \\
\hline
\end{tabular}


Table 4: Comparison of the existing with the projected specialist manpower

\begin{tabular}{|c|c|c|c|c|c|c|c|}
\hline Speciality & $\begin{array}{l}\text { Estimate } \\
\text { In } 2003\end{array}$ & $\begin{array}{l}\text { GoN } \\
2003\end{array}$ & $\begin{array}{l}\text { NMC } \\
2003\end{array}$ & $\begin{array}{l}\text { NMC } \\
\mathbf{2 0 0 7}\end{array}$ & $\begin{array}{c}\text { GoN } \\
2017 \\
\text { (projected) }\end{array}$ & $\begin{array}{c}\text { Private } \\
2017 \\
\text { (projected) }\end{array}$ & $\begin{array}{c}\text { Total for } \\
2017 \\
\text { (projected) }\end{array}$ \\
\hline Anaesthesiology & 98 & 37 & 35 & 59 & 62 & 90 & 152 \\
\hline Cardiology & 43 & 16 & 33 & 53 & 16 & 49 & 65 \\
\hline Clinical Pathology & 44 & 49 & 13 & 36 & 69 & 6 & 75 \\
\hline $\begin{array}{l}\text { Community Medicine / Public } \\
\text { Health }\end{array}$ & 98 & 106 & 7 & 21 & 106 & 24 & 130 \\
\hline Dental Surgery - BDS & 105 & 39 & 16 & 662 & 39 & 119 & 158 \\
\hline Dental Surgery - Masters & - & - & - & 43 & - & - & - \\
\hline Dermatology / Venereology & 17 & 17 & 1 & 32 & 17 & 53 & 70 \\
\hline Endocrinology & 2 & 2 & - & - & 2 & 1 & 3 \\
\hline ENT & 53 & 19 & 22 & 39 & 39 & 60 & 99 \\
\hline Forensic Medicine & - & - & - & 3 & - & - & - \\
\hline Gastroenterology & 14 & 6 & 9 & 12 & 6 & 16 & 22 \\
\hline General Practice & 30 & 5 & 29 & 64 & 43 & 34 & 77 \\
\hline General Surgery & 129 & 50 & 60 & 144 & 93 & 145 & 238 \\
\hline Gerontology & 1 & 1 & - & - & 1 & 0 & 1 \\
\hline Cardio Thoracic Surgery & 11 & 4 & - & - & 4 & 12 & 16 \\
\hline Neuro Surgery & 11 & 4 & - & - & 4 & 12 & 16 \\
\hline Internal Medicine & 118 & 44 & 39 & 88 & 87 & 134 & 221 \\
\hline Medicine - Tropical & 11 & 3 & - & - & 3 & 12 & 15 \\
\hline Microbiology & - & - & - & 2 & - & - & - \\
\hline Nephrology & 8 & 3 & 4 & 4 & 3 & 9 & 12 \\
\hline Neurology & 7 & 3 & 7 & 8 & 3 & 8 & 11 \\
\hline Nuclear Medicine & 5 & 6 & - & 3 & 6 & 0 & 6 \\
\hline Obstetrics \& Gynaecology & 204 & 76 & 78 & 156 & 140 & 181 & 321 \\
\hline Oncology & - & - & 3 & 3 & - & - & - \\
\hline Surgical Oncology & - & - & - & 7 & - & - & - \\
\hline Ophthalmology & 106 & 39 & 38 & 60 & 44 & 121 & 165 \\
\hline Orthopaedics & 60 & 22 & 31 & 95 & 32 & 68 & 100 \\
\hline Paediatrics & 177 & 65 & 77 & 121 & 129 & 201 & 330 \\
\hline Paediatric Surgery & 8 & 3 & - & - & 3 & 9 & 12 \\
\hline Pharmacology & & & 2 & 7 & & & \\
\hline Psychiatry & 32 & 13 & 11 & 25 & 13 & 36 & 49 \\
\hline Plastic Surgery & 7 & 3 & - & - & 3 & 8 & 11 \\
\hline Radiology \& Imaging & 59 & 37 & 31 & 58 & 52 & 38 & 90 \\
\hline $\begin{array}{l}\text { TB \& Respiratory Dis. / } \\
\text { Pulmonology }\end{array}$ & 30 & 11 & 2 & 5 & 11 & 34 & 45 \\
\hline Urology / Urosurgery & 16 & 6 & 5 & 9 & 6 & 18 & 24 \\
\hline
\end{tabular}


NB. Specialist registration has picked up since 2003 hence the marked increase in certain disciplines. What must be noted however, is that a person may be registered by a category e.g. internal medicine or by a speciality e.g. neurology. There is thus, still further need of looking at this categorisation of specialists as has been done by the NMC. It is interesting to note that not many specialists of Basic Sciences have registered so far. Expatriate teachers working on contract basis in Nepal have not been included here.

The simple increase in the numbers of institutions and health manpower is not going to solve the problems. It is the delivery of health care to the people that matters.

\section{Areas of concern (weaknesses)}

Nepal has seen major changes in the field of training of health professionals over the last 15 years. This field has attracted significant private investment and a number of training institutions with hospitals, have come into existence. However, the trend of opening new institutions is continuing. Not only is it likely to be detrimental to the existing facilities but it is also raising doubts about the quality and standards of some of the institutions in the private sector ${ }^{10}$ thus earning the epithet "mushrooming of medical colleges". The pliable Universities and Councils have favoured accelerating the business of medical education. It is therefore not surprising that many of those involved in establishing the money-spinning colleges have the intention of turning medical institutions as a lucrative source of income.

The problems that have risen and will also arise in the future may be considered under three headings:

\section{a. General}

The President of the Nepal Medical Association, at the time of the $15^{\text {th }}$ Medical Conference at Biratnagar in 1991 had talked about the 'Health Rights of the People'. Seventeen years have now elapsed from that point of time. It is now a matter of satisfaction that 'Basic Health as Human Right' has been incorporated in the interim constitution of Nepal. Will it be the responsibility of the central government or of the autonomous regions of the country? Do we have to wait till we have a new constitution, which specifies these points? Obviously there has to be a Public/Private mix for this endeavour.

\section{b. Educational Sector}

Whilst a large percentage of the specialists for the clinical areas pay for their own training, there is a shortage of candidates for the basic sciences. Not many want to be teachers in these areas. Is it the lack of private practice that discourages young doctors from entering such fields? The medical, dental and nursing schools are coming up literally like mushrooms growing in a dark environment. We are told that because Nepal has become a member of the World Trade Organisation (WTO) there is no way that one can restrict or curtail the starting of institutions in the health or education sector. The Universities are giving affiliations and the Nepal Medical Council (NMC) is doing its regulatory inspections. These are cursory and more in the nature of counting the heads of teachers rather than in the manner of an accreditation format, which entails examining what should have been taught or be taught and what the final product is like. To tackle the present shortage, both the University concerned and the NMC should allow teachers in Basic Science subjects like Anatomy, Biochemistry and Physiology to teach and be counted as faculty in at least one other institution beside their own. The aim of the Universities and the Councils should be to aid the institution that is being built and established in the country.

What should be realised is that it is very difficult to get medical personnel to take up the study of Anatomy, Physiology, Biochemistry and even Microbiology. Nonmedical experts should be encouraged to be teachers in these areas. Some other options might even be to:

a. Amalgamate / take over existing colleges so that the number of such institutions in the country decrease and get more efficient.

b. Let some colleges undertake to do the first two years only or alternatively to train more students in basic sciences than they have places for clinical study. Such students will go to a different college for the clinical part of training. Actually some colleges could concentrate on basic sciences only. Those involved in doing preclinical teaching should be given incentives.

The second category is that of PG in the different specialities that are the requirements of the country. Their quality will depend on where they have been trained and the facilities that they had whilst training. In some instances the PGs are not allowed to operate / treat the patient that they are looking after. They have to come to Nepal to do their practical training without any sort of supervision. This sort to training arrangement should not be encouraged or accepted.

\section{c. Service sector}

The ever occurring increases of the population of Nepal which has risen over the years, coupled with the increase in the number of health institutions has been accompanied by increase in different categories of health workers. These institutions which may be both producing and utilising HRH have brought forth many problems which have to be solved promptly if a crisis is not to occur. 
When we are contemplating the establishment of a large number of teaching and service institutions in different parts of the country it is worthwhile to compare the existing with the projected specialists manpower.

NB. The estimates for 2017 were made at a time when the requirements of medical colleges were not known. There is overlap of categories in that internal medicine specialists will be practicing tropical medicine in Nepal! Thus the total of these numbers has not been made as some specialists have obviously been included in two categories.

\section{Future consequences (Threats)}

It is to be realised that with the increase in medical and dental colleges / schools in the country there is going to be a large production and requirement of human resources of health (HRH). The number of young doctors from Nepal who were going to the UK has decreased drastically because preference is being given to doctors from the European Union countries. A number of Nepali doctors are doing the United States medical license examination (USMLE) and going to the States but what must be noted is that a certain percentage has now started coming back. One does not know the cause of this - whether it is dissatisfaction with working conditions, homesickness or unwillingness to keep up with the fast pace of life there. This trend has taken place in India too. For young Nepali doctors the country to go to now seems to be Australia. Prospects for work overseas seem to be much better and enlarging for nurses though most are going as care givers to geriatric patients rather than for work in the hospitals.

So even as we open more medical colleges, we must be aware that possibility also exits for:

i. The number of foreign students coming to Nepal to study medicine may decrease as these countries are opening more teaching institutions in their lands

ii. The demands for places in medical schools will decrease as newly qualified doctors realise that they are not going to get jobs easily.

Somehow there is a tendency in Nepal for people to go on into a line of business, which they see as flourishing with perhaps a good chance of quick returns. The truth of the matter is that there is a large investment to be made, with prospects of returns only after a number of years. All investors seem to quickly see the money coming in, in the form of student fees but the cost of running a fully fledged modern, well equipped state of the art hospital is not immediately apparent. There has also to be provision for free treatment, especially of the poor patients. As the late Mrs. Indira Gandhi once said, "It is the poor who have the disease". It is these patients that the medical colleges are morally obliged to treat for it is these simple folks on whom the future budding doctors are being taught. Furthermore, because of the development of information technology, many persons are aware of what can be achieved in terms of treatment. What many do not realise is that all of what we see and hear about as standard, regular medical treatment in foreign lands cannot always be replicated here in Nepal. The conditions are worse in rural areas. This is where the trouble is as far as the health workers of Nepal are concerned for the usual situation is lack of equipment and facilities. No wonder that many personnel are absent in health institutions and young medical graduates on whose medical education parents have spent 20 to 25 lakhs sees no prospect of recouping their investment. Having been trained in urban areas he has a fear for the rural areas and is loathe to go there. This is what entices him to look for a job in the cities and scout for prospects abroad. He reckons that he too will be better off there as a modern 'lahure'.

In the olden days when one asked the newly qualified SLC students what they wanted to be in the future they invariably said that they would take science and become either a doctor or an engineer. Now being confronted by a demanding public and bystanders ready to victimise doctors it is likely that candidates for the healing profession are likely to very much decrease in the future.

\section{Ideas for the future (Opportunity)}

The concept of medical and educational tourism is very good and a well worthwhile undertaking. Patients from UK, USA and Gulf countries are coming to some of the renowned institutions of India for service. Great efforts have been made and large strides taken. It is not just the construction of buildings and the display of equipment that will attract the customers, the patients. It is the marvels of surgery, wonders of the drugs used, the quality of care given and the results of treatment. News of such successes goes more by way of mouth, accompanied by extensive publicity. Many a newly established education institution in India caters to the needs of many of the Non Resident Indians (NRI) who want their children to imbibe some of the culture of the home country. It has taken years for this to occur.

There had been talk of building a 'Health City' in Bharatpur. We in Nepal are relatively new in this field of medical tourism. Our institutions for eye care have been successful in attracting patients from India partly because of the long experience and expertise of providing ophthalmic services. Institutions for cardiac and neurological care are just coming up but 'one swallow does not make a summer'. What must be faced is that we have too few dedicated manpower to bring this about. 


\section{Conclusion}

In the health field the institutions are just finding their feet. Our experts and our institutions have still to prove their worth and word of their expertise have still to get around. The prospective customers for these health and also educational institutions within Nepal are the Non Resident Nepalese (NRN). Unfortunately, the pool of such prospective clients is currently too small and most of them are in lowly paid jobs are not in a position to utilise our services. Many of the ex-Gurkha soldiers now settled abroad are an exception to this. The fact that most of our educational institutions are affected or made to close by such incidents as 'bandhs' does not send a healthy message to such customers. Eventually, we have to be optimistic that quality in education and health care will prevail, that the best will stay and survive in the long run for the betterment of the country.

\section{Acknowledgement}

Thanks are to Drs. Jagdish Agrawal, Keshav D Joshi, Shekhar Babu Rizyal for having gone through the initial drafts of the paper and given suggestions for improvement.

\section{References}

1. Central Bureau of Statistics. Health Information Bulletin. 1992; 3.

2. CIA. The World Factbook - Nepal [homepage on the internet]. Washington DC: CIA; [cited 2008 Aug 15]. Available from: https://www.cia. gov/library/publications/the-world-factbook/ print/np.html

3. UNDP. Human Development Reports- United Nations Development Programme [homepage on the internet]. New York: UNDP; [cited 2008 Aug 15]. Available from: http://hdr.undp.org/ en/
4. WHO. World Health Report for 2006. WHO; 2006.

5. David R. Hotchkiss Expansion of rural health care and the use of maternal services in Nepal Health \& Place. Nepal Health \& Place. 2001; 7(1): 39-45.

6. IRIN. Humanitarian news and analysis [homepage on internet]. PLACE: IRIN; [cited 2008 Aug 15]. Available from: http://www. irinnews.org/Asia-Country.aspx?Country=NPA

7. School of Medical Sciences, Kathmandu University. Report on Present Status of Medical Education in Nepal: Need for the Twenty-first Century. Kathmandu: Kathmandu University; January 2006.

8. Dixit H. Nepal's Quest for Health. Kathmandu: Educational Publishing House; 2005.

9. Dixit H. Role of Nepal Medical Council in MBBS Curriculum. KUMJ. 2003;1(1): 66-71.

10. Adhikari RK. Privatization in Technical Education: The Case of Education of Health Professionals in Nepal. Regional Health Forum. 2006; 10:59-64. 